\title{
Cardiac adrenergic neuronal activity, sleep apnea, and potential therapeutic role of nocturnal ventilatory assistance in patients with heart failure
}

\author{
Diwakar Jain, MD, FACC, MASNC \\ a Section of Cardiovascular Medicine, New York Medical College and Westchester Medical \\ Center, Valhalla, NY
}

Received Feb 6, 2018; accepted Feb 6, 2018

doi: $10.1007 / \mathrm{s} 12350-018-1234-7$

\section{See related article, pp. 1079-1089}

Breathing disorders during sleep are common. Patients with congestive heart failure $(\mathrm{CHF})$ and systolic dysfunction have a high prevalence of sleep disorder breathing. ${ }^{1-7}$ This is mainly in the form of Cheyne Stokes breathing and central sleep apnea (CSA). CSA is characterized by a dysregulated and insufficient drive for breathing during sleep, resulting in repetitive episodes of insufficient ventilation and inadequate gas exchange. There are frequent episodes of hyperventilation followed by apnea associated with a drop in $\mathrm{O}_{2}$ saturation, sleep fragmentation, and arousals. Another form of sleep disorder or obstructive sleep apnea (OSA) is also common in general population. ${ }^{8-10}$ This mainly comprises of episodes of increased resistance and obstruction in the upper airways, a rise in negative intra-thoracic pressure, ineffective ventilation, hypoxia, and arousals. A major distinction between CSA and OSA is an insufficient respiratory drive in the former, whereas there is ineffective respiratory drive in the later. OSA is more commonly seen in the overweight patients and in those with increased neck circumference. Both forms of sleep apnea cause daytime drowsiness and poor quality of life. Whereas both forms of sleep apnea have distinct mechanism, nevertheless, both result in disturbance of

Reprint requests: Diwakar Jain, MD, FACC, MASNC, Section of Cardiovascular Medicine, New York Medical College and Westchester Medical Center, 100 Woods Road, Valhalla, NY; dj2700@gmail.com

J Nucl Cardiol 2019;26:1090-2.

1071-3581/\$34.00

Copyright (C) 2018 American Society of Nuclear Cardiology. sleep architecture, episodes of hypoxia, sympathetic activation, daytime drowsiness, and have been associated with systemic hypertension, pulmonary hypertension, supraventricular and ventricular arrhythmias, left ventricular remodeling, and adverse cardiovascular events. There is a significant degree of overlap between the two types of sleep apnea. Both forms of sleep apnea are diagnosed by the detection of episodes of apnea or hypopnea (AHI) on a sleep study. Detection of $\geq 15$ episodes of apnea or hypopnea per hour during sleep study is used as a threshold for the diagnosis of sleep apnea. When $\geq 50 \%$ of the episodes of AHI are central in origin, this is arbitrarily classified as CSA. The prevalence of CSA has been estimated to be in over one-third of patients with CHF. Both forms of sleep apnea have attracted a lot of investigative and therapeutic interest. Continuous positive airways pressure-assisted ventilation (CPAP) is the most common form of respiratory assistance used in patients with OSA, whereas adaptive servo ventilation (ASV) is the most commonly used ventilatory assistance in patients with CSA. ${ }^{1,3,7}$ The later is an algorithm driven close loop ventilator system designed to maintain normal breathing pattern in patients with CSA. Different manufactures use different algorithms in their adaptive ventilator devices, but they all achieve the same goal of maintaining a normal breathing pattern in patients with CSA.

Several smaller studies have shown beneficial effects of ASV in subjective parameters of reduced daytime drowsiness and uninterrupted sleep in patients with CHF and CSA. ${ }^{1,3,4,11}$ In addition, several parameters of cardiac performance as well as neuroendocrine abnormalities associated with CHF have also shown an improvement with the use of these ventilatory 
devices. ${ }^{2,4}$ This has resulted in an increasing use of these ventilator systems in patients with $\mathrm{CHF}$ and CSA.

In order to determine the definitive role of ASV in patients with $\mathrm{CHF}$ and CSA, a large multicenter randomized study (SERVO-HF study) has recently been conducted and published. ${ }^{12}$ SERVO-HF study included NYHA II-IV CHF patients with $\mathrm{LVEF} \leq 45 \%$, and, AHI $>15 /$ hour with $\geq 50 \%$ being central events and central $\mathrm{AHI} \geq 10 /$ hour. The study randomized 1325 patients to treatment with ASV during sleep or no assisted ventilation (control group). The primary endpoint was the time to the onset of an adverse event (composite endpoints of: all-cause mortality, heart transplant, worsening CHF requiring implantation of a ventricular assist device, appropriate shock(s) in patients with an internal cardiac defibrillator (ICD), and unplanned hospitalization for worsening CHF). No significant difference was observed between the ASVtreated and the control group on the primary endpoint, despite a remarkable reduction of AHI and a subjective improvement in the ASV group. Unexpectedly, a higher cardiovascular mortality was observed in the ASV group compared to the control group (10\% vs $7.5 \%)$, corresponding to a $33 \%$ increase in the relative risk of cardiovascular mortality in the ASV group. Most of the excess mortality was due to sudden deaths. This risk remained constant over time and was independent of the symptomatic improvement experienced by the patients in the ASV group. These results defied the expectation of an improvement in adverse cardiac events with the use of ASV in patients with CSA. The exact reason for increased cardiac mortality with the use of ASV in patients with $\mathrm{CHF}$ and CSA, despite a significant reduction in AHI and a subjective improvement, is not clear at this point. This is the subject for intense debate, further sub-analyses, new speculations regarding the mechanism of CSA and more research studies. ${ }^{6,12-16}$

Based upon the findings of this study, safety warnings and advisories against the use of ASV in patients with $\mathrm{CHF}$ and CSA have been issued by several professional societies in the USA, and in several European countries. ${ }^{14,15}$ Similar safety warnings have also been issued by the manufacturers of the ASV devices. ${ }^{15}$ Despite differences in the algorithms used by different manufactures, there is an agreement about not using any ASV in patients with systolic HF (NYHA II-IV) with $\mathrm{LVEF} \leq 45 \%$ with mainly CSA (central events $\geq 50 \%$ of $\mathrm{AHI})$.

In this issue of the Journal, Tokuda and colleagues have published a study of nine patients with $\mathrm{CHF}$ (NYHA class II and III, and sleep apnea, who were treated with ASV for 6 months). ${ }^{17}$ They studied the left ventricular function by echocardiography, cardiac adrenergic neuronal function by ${ }^{123} \mathrm{I}-\mathrm{MIBG}$ and
${ }^{11} \mathrm{C}$-HED imaging, plasma BNP concentration, urinary and plasma catecholamines at baseline and after 6 months of therapy with ASV. ASV therapy significantly improved AHI and also improved BNP levels. On imaging studies, there was a small and statistically insignificant improvement in the left ventricular ejection fraction $(36 \% \pm 5 \%$ to $39 \% \pm 5 \%, P=$ ns $)$. Heart-tomediastinal ratio on early ${ }^{123} \mathrm{I}-\mathrm{MIBG}$ imaging improved from $2.19 \pm 0.58$ to $2.40 \pm 0.67(P=0.045)$; there was no change in this ratio on delayed imaging, neither was any change in myocardial ${ }^{123}$ I-MIBG washout rate across 15 minute and 4 hour imaging. On ${ }^{11} \mathrm{C}$-HED cardiac PET imaging, an improvement in myocardial tracer retention at 30 to 40 minute imaging was observed $0.068 \pm 0.033 / \mathrm{s}$ to $0.075 \pm 0.034(P=0.029)$. Based upon these results, the authors conclude that ASV might improve presynaptic cardiac sympathetic neurona function in patients with $\mathrm{CHF}$.

Whereas the results of this study are interesting and highlight the potential of novel molecular imaging modalities in addressing complex clinical questions, however, several limitations need to be kept in mind, while drawing any conclusions from this study. The small sample size does remain a significant limitation. The authors aimed to study the changes in cardiac sympathetic function with ASV in patients with $\mathrm{CHF}$ and sleep apnea. However, only 6 out of 9 patients met the criteria for sleep apnea. Of these 5 had OSA and only 1 had CSA. The rationale for the use of assisted ventilation in patients with no sleep apnea is unclear. Furthermore, ASV is recommended for CSA, the reason for choosing ASV rather than CPAP in patients with predominantly OSA is not clear? Of several imaging and non-imaging parameters of cardiac sympathetic function studies by the authors, only early heart-to-mediastinal ratio on ${ }^{123}$ I-MIBG imaging and 30 to 40 minute ${ }^{11} \mathrm{C}$-HED myocardial retention showed a small change, whereas other showed no change. With the recent finding of increased cardiac mortality with the use of ASV in patients with $\mathrm{CHF}$ and CSA and a strong advisory against this use, one needs to exercise caution while interpreting these results. Perhaps, the relationship between CHF and sleep disorders is a lot more complex than a simple cause and effect relationship. Treatments directed towards an epiphenomenon of a basic disease process may not modify the natural history of the basic disease process and may even result in harm because of their effect on other biological processes. The field of cardiology learnt it the hard way via several large research studies, while evaluating the role of anti-arrhythmic agents for the treatment arrhythmias in patients with heart disease and, and for the use of inotropic agents in patients with CHF. ${ }^{18-20}$ Perhaps, a better understanding of the nature of relationship between $\mathrm{CHF}$ 
and sleep disorders is required before we can identify targets for therapy to favorably modify the natural history of $\mathrm{CHF}$.

\section{Disclosure} disclose.

The author declares that there is no conflict of interest to

\section{References}

1. Eckert DJ, Jordan AS, Merchia P, et al. Central sleep apnea. Pathophysiol Treat Chest. 2007;131:595-607.

2. Costanzo MR, Khayat R, Ponikowski P, et al. Mechanisms and clinical consequences of untreated central sleep apnea in heart failure. J Am Coll Cardiol. 2015;65:72-84.

3. Sharma BK, Bakker JP, McSharry DG, et al. Adaptive servoventilation for treatment of sleep-disordered breathing in heart failure: A systematic review and meta-analysis. Chest. 2012; 142:1211-21.

4. Jilek C, Krenn M, Sebah D, et al. Prognostic impact of sleep disordered breathing and its treatment in heart failure: An observational study. Eur J Heart Fail. 2011;13:68-75.

5. Damy T, Margarit L, Noroc A, et al. Prognostic impact of sleepdisordered breathing and its treatment with nocturnal ventilation for chronic heart failure. Eur J Heart Fail. 2012;14:1009-19.

6. Naughton MT. Cheyne-Stokes respiration: Friend or foe? Thorax. 2012;67:357-60.

7. Cowie MR, Woehrle $\mathrm{H}$, Wegscheider $\mathrm{K}$, et al. Rationale and design of the SERVE-HF study: Treatment of sleep-disordered breathing with predominant central sleep apnoea with adaptive servo-ventilation in patients with chronic heart failure. Eur J Heart Fail. 2013;15:937-43.

8. Mohsenin V. Obstructive sleep apnea and hypertension: A critical review. Curr Hypertens Rep. 2014;16:482. https://doi.org/10.1007/ s11906-014-0482-4.

9. Vranish JR, Bailey EF. Inspiratory muscle training improves sleep and mitigates cardiovascular dysfunction in obstructive sleep apnea. Sleep. 2016;39:1179-85. https://doi.org/10.5665/sleep.5826.
10. Barbe F, Duran-Cantolla J, Sanchez-de-la-Torre M, et al. Effect of continuous positive airway pressure on the incidence of hypertension and cardiovascular events in nonsleepy patients with obstructive sleep apnea: A randomized controlled trial. JAMA. 2012;307:2161-8

11. Aurora RN, Chowdhuri S, Ramar K, et al. The treatment of central sleep apnea syndromes in adults: Practice parameters with an evidence-based literature review and meta-analyses. Sleep. 2012;35:17-40.

12. Cowie MR, Woehrle H, Wegsscheider K, et al. Adaptive servo-ventilation for central sleep apnea in systolic heart failure. N Engl J Med. 2015;373:1095-105. https://doi.org/10.1056/NEJMoa1506459.

13. Magalang UJ, Pack AI. Heart failure and sleep disordered breathing: The plot thickens. N Engl J Med. 2015;373:1166-7.

14. Ayas T, Patil SP, Stanchina M, et al. Treatment of central apnea with adaptative servoventilation in chronic heart failure. Am J Respir Crit Care Med. 2015;192:132-3.

15. Priou P, d'Ortho MP, Damy T, et al. Adaptive servo-ventilation: How does it fit into the treatment of central sleep apnoea syndrome? Expert Opin Rev Mal Respir. 2015. https://doi.org/10.1016/j.rmr. 2015.09.007.

16. Cowie MR, Woehrle H, Wegscheider $\mathrm{K}$, et al. Adaptive servoventilation for central sleep apnoea in systolic heart failure: Results of the major sub-study of SERVO-HF. Eur J Heart Fail. 2017. https://doi.org/10.1002/ejhf.1048.

17. Tokuda Y, Sakaibara M, Yoshinaga K, et al. Early therapeutic effects of adaptive servo-ventilation on cardiac sympathetic nervous function in patients with heart failure evaluated using a combination of ${ }^{11} \mathrm{C}$-HED PET and ${ }^{123}$ I-MIBG imaging. J Nucl Cardiol. 2018. https://doi.org/10.1007/s12350-017-1132-4.

18. Teo KK, Yusuf S, Furberg CD. Effects of prophylactic antiarrhythmic drug therapy in acute myocardial infarction: An overview of results from randomized controlled trials. JAMA. 1993;270:1589-95.

19. Boriani G, Diemberger I, Valzania C, et al. Role of drugs and devices in patients at risk of sudden cardiac death. Fundam Clin Pharmacol. 2010;24:575-94. https://doi.org/10.1111/j.1472-8206. 2010.00853.x.

20. Aronow WS. Current treatment of heart failure with reduction of left ventricular ejection fraction. Expert Rev Clin Pharmacol. 2016;9:1619-31. 